\title{
Examination of the Energy Efficiency of Wall Building Elements Used in Dwellings
}

\author{
I. Vural*, T. Akgul, E. Aydin, F. Aydin, M. Saribiyik \\ Sakarya University, Technology Faculty, Department of Civil Engineering, 54187, Sakarya, Turkey
}

\begin{abstract}
In this study, within the scope of the number of studies related to the efficient use of energy increasing day by day, the thermal insulation performance of wall elements used in dwellings was determined using experimental methods. With this aim, a $1 / 3$ scaled reinforced concrete structure with the complete characteristics of an actual structure, was built and the column spans were filled using six different types of wall element. These materials, widely used in dwelling production in Turkey, were applications of horizontal coring bricks, vertical coring bricks, pumice, gas concrete, block brick and a cavity wall. The interior temperature was kept constant by placing a thermal source inside the built sample construction and the temperatures for different exterior temperatures were measured with a thermocouple and camera from each wall surface. Thus, by interpreting the obtained surface temperature data, the energy efficiency of the wall types used was presented, the thermal conductivity resistance, thermal conductivity coefficient, and loss of heat as regards to TSE 825 were calculated and accordingly, the thermal conductivity performances of walls were compared.
\end{abstract}

DOI: 10.12693/APhysPolA.127.1417

PACS: 81

\section{Introduction}

Energy consumption is rapidly increasing due to changes such as growing population urban development and life quality improvement. Major factors such as transportation, agriculture and cultivation, industrial development and the construction of commercial or dwelling settlements affect the concept of energy consumption [1]. Among these, the building sector is the industrial sector with the greatest consumption potential. The building sector (together with the industrial sector) has become the world's dominant energy consumer with a $28 \%$ share of overall energy consumption $[2,3]$. Therefore, many countries reserve the biggest share of energy consumption for the heating or cooling of buildings $[4,5]$.

The basic purpose of using thermal insulation in dwellings is to keep the annual energy consumption level as low as possible. Consequently, the primary and most important practice is the insulation of all exterior surfaces of the building as well as roof, wall and foundation sections [6]. Although the ratio of heat loss varies according to the number of storeys in the structure, heat losses in buildings (for multi-storey buildings) of $40 \%$, $30 \%, 17 \%, 7 \%$, and $6 \%$ have been substantiated, respectively, through walls, windows, air leaks, roofs and basement floors $[7,8]$. The fact that the biggest amount of heat loss is caused by the exterior walls in dwellings increases the significance of determining the suitable wall elements. Therefore, knowing the energy efficiency performance of the wall elements used in exterior walls and accordingly taking the necessary precautions would enable significant gains. The studies regarding thermal insulation in dwellings generally concentrate on examin-

\footnotetext{
*corresponding author; e-mail: ivural@sakarya.edu.tr
}

ing the performance of the thermal insulation materials used [9] or determining the optimum thickness [10-13].

\section{Materials and method}

In order to examine the heat losses of materials used for wall bonding elements, a $1 / 3$ scaled reinforced concrete framed structure with the characteristics of an actual dwelling was first set up (Fig. 1). In the model structure, the column and beam sizes were taken as $18 \times 20 \mathrm{~cm}$ and $15 \times 20 \mathrm{~cm}$, respectively, while the building height was taken as $100 \mathrm{~cm}$. On the exterior walls of this model frame system, 6 spans between axes were the designed and the spans between each couple of axes were filled with one of the most preferred materials used for wall elements in dwellings. The materials chosen were horizontal coring bricks, vertical coring bricks, pumice, gas concrete, block brick and a cavity wall application. In order to determine the heat losses inside the built model structure precisely, the structure was settled on an OSB plate raised $5 \mathrm{~cm}$ above the ground so as to prevent the heat losses that might occur on the floor. Above the upper reinforced concrete panel, $5 \mathrm{~cm}$ thick fiberglass layer was applied. To protect the fiberglass applied on the roof from the exterior factors, a waterproof membrane was applied over the material. The three dimensional design of the built system can be seen for vertical coring bricks, block brick and cavity wall in Fig. 1a and the three dimensional design of the built system can be seen for gas concrete, pumice, horizontal coring bricks in Fig. 1b. To prevent the possible heat losses in the built system, a $3 \mathrm{~cm}$ thick scratch coat layer was applied on the exterior walls. The thicknesses of walls built from the different materials and the thermal conductivity calculation values belonging to these materials are given in Table. Since pumice, unlike other materials, is manufactured with $15 \mathrm{~cm}$ thickness, the material was also used with $15 \mathrm{~cm}$ thickness in the experimental studies. 


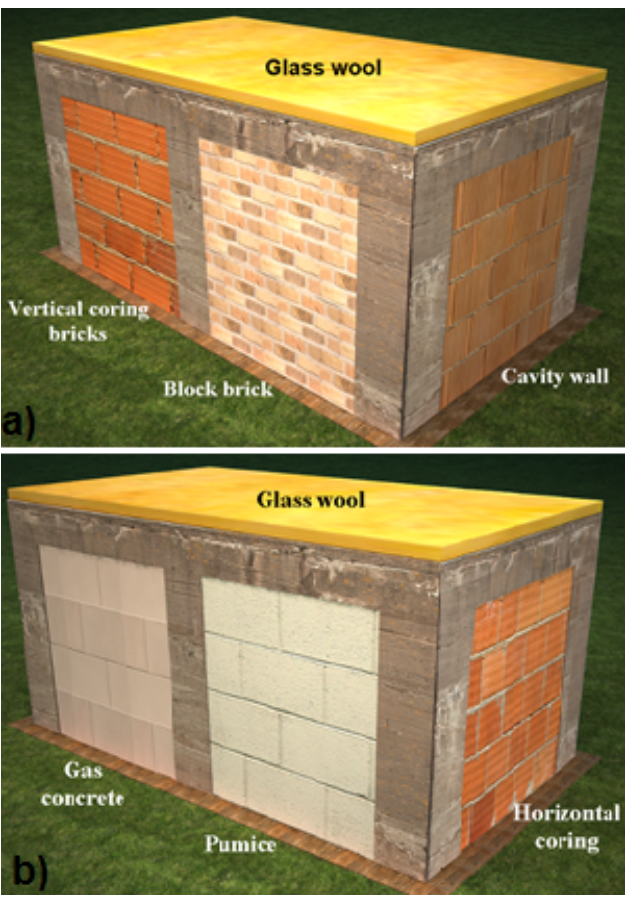

Fig. 1. Three-dimensional design for the example building (a) Vertical coring bricks, block brick and cavity wall (b) Gas concrete, Pumice, Horizantal coring bricks.

\section{Experimental studies}

The experimental studies were implemented in the winter season and a heat source was placed inside the structure to conserve the inner comfort temperature. The inner temperature was kept constant by using a thermostat that could be controlled externally. With the use this thermostat, it was possible to keep the inner temperature at the same level at all times and this situation was controlled at all times via thermal sensors placed inside. After the inner temperature was set, the temperatures on the exterior surfaces of the walls were measured for different exterior temperatures. These measurements were implemented with the help of a $\mathrm{K}$ type thermocouple device and thermal cameras that could measure temperature values between -20 and $+200^{\circ} \mathrm{C}$. The measurements on the walls' exterior surfaces were implemented in the winter days when there is no sun effect, and especially during certain morning or evening hours in the shade. Therefore, errors caused by the direction effect were averted. While keeping the inner temperature constant at $25{ }^{\circ} \mathrm{C}$, thermal camera images were taken from each wall surface from a distance of approximately $5 \mathrm{~m}$. Using these images transferred to the computer medium, mean wall surface temperature values were obtained using Therma CAMQuickView packaged software. The thermal camera shots taken on the exterior wall surfaces can be seen in Fig. 2. When Fig. 2 is examined, it was determined that the mean exterior surface temperature of the wall built with $19 \mathrm{~cm}$ thick gas concrete blocks was $6.9^{\circ} \mathrm{C}$ (Fig. 2c), while the mean exterior surface temperature of the cav-
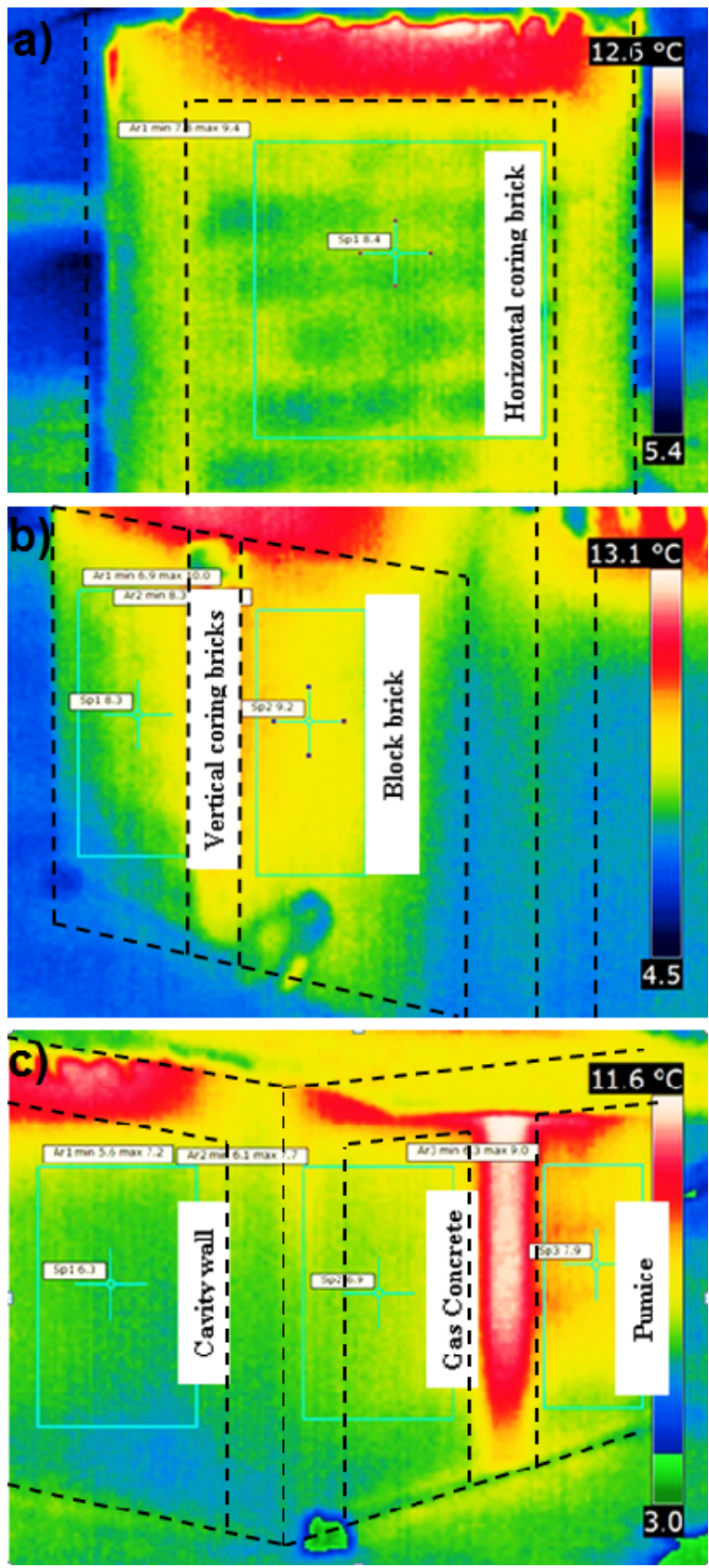

Fig. 2. Thermal camera images of the wall (a) horizontal coring brick thermal image (b) vertical coring bricks and block brick thermal image (c) cavity wall, gas concrete and pumice thermal image.

ity wall, built by applying $3 \mathrm{~cm}$ Styrofoam between two $8.5 \mathrm{~cm}$ thick horizontal coring bricks, was measured as $6.3{ }^{\circ} \mathrm{C}$ (Fig. 2a). The mean exterior surface temperature of the $15 \mathrm{~cm}$ thick pumice block wall, on the other hand, was determined as $7.9{ }^{\circ} \mathrm{C}$ (Fig. 2c). Likewise, the mean exterior surface temperature of the vertical coring brick wall was measured to be $8.3{ }^{\circ} \mathrm{C}$, whereas the same temperature value was $9.2{ }^{\circ} \mathrm{C}$ for the block brick wall (Fig. 2b). It was observed from the image obtained from the horizontal coring brick wall that the mean ex- 
terior surface temperature was $8.4{ }^{\circ} \mathrm{C}$. This value was found to be the same for the vertical coring brick which is manufactured using the same material. Furthermore, along with the thermal camera images, the exterior surface temperature values were taken using thermocouple device sensors. Two measurements were taken once a day from each wall surface using a thermocouple at different exterior temperatures for 30 days in the winter months. The temperature inside the model structure was kept constant at $25{ }^{\circ} \mathrm{C}$ with a thermostat with the aim of determining the most efficient wall type among the 6 different wall types for varying exterior temperatures. The thermal performances of the wall elements were evaluated by calculating the mean values of measurements obtained from each wall surface; thus, the graphic was created (Fig. 3). When the Fig. 3 is examined, the most

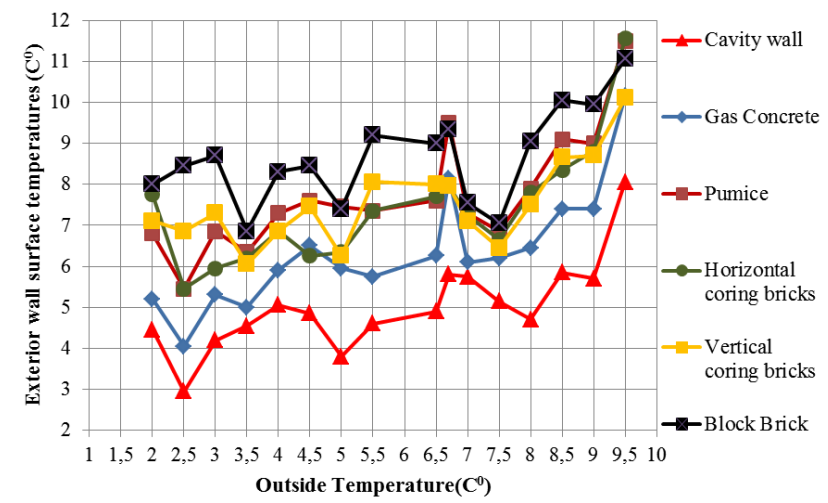

Fig. 3. Exterior wall surface temperatures measured by thermocouple.

efficient wall building element was the cavity wall type for temperatures between $10{ }^{\circ} \mathrm{C}$ and $100{ }^{\circ} \mathrm{C}$ independent from the humidity and wind factors for study region. As a result of the massive internal structure, the block brick was determined to be the wall type with the most heat losses. The use of Styrofoam between two $8.5 \mathrm{~cm}$ thick bricks in the cavity wall decreases the heat losses; when compared with the other applications, it stands out in terms of energy efficiency. With the values obtained as a result of all these measurements, the heat losses were calculated by considering the details provided in TS 825 [16] and related regulations. The thermal conductivity resistance, the thermal conductivity coefficient and amount of heat loss was calculated for each wall surface. In the calculations, Eq. 3.1 was used for thermal conductivity resistance.

$$
R=d_{1} / \lambda_{h 1}+d_{2} / \lambda_{h 2}\left(\mathrm{~m}^{2} \mathrm{~K} / \mathrm{W}\right)
$$

In this formula, $d_{1}$ and $d_{2}$ were taken as the wall thickness values, while $\lambda_{h 1}$ and $\lambda_{h 2}$ represent the thermal conductivity calculation values of the materials. However, the total thermal resistance coefficient belonging to the structural element was calculated using Eq. 3.2.

$$
U_{D}=1 /\left(R_{i}+R+R_{e}\right)\left(\mathrm{W} / \mathrm{m}^{2} \mathrm{~K}\right)
$$

$R_{i}$ and $R_{e}$, taken from TS 825 , represent the thermal conductivity resistance values of internal and external surfaces, respectively. $R$ value, on the other hand, is the value obtained from Formula 1 for different material types and the thickness of the wall elements of the sample structure. Lastly, by using measurements conducted on the walls of the sample structure with the help of both a thermal camera and thermal sensors $\left(t_{1}, t_{2}\right)$ and the thermal conductivity coefficients $\left(U_{D}\right)$ of the walls obtained for each material above, the heat loss per $\mathrm{m}^{2}$ wall surface occurring with conventional methods was calculated using Eq. 3.3 [17].

$$
Q=U_{D} \Delta t\left(\mathrm{~W} / \mathrm{m}^{2}\right)
$$

As a result of the calculations, thermal conductivity resistance, the thermal conductivity coefficient and amount of heat loss for each uninsulated wall material are presented in Table. When the $U_{D}$ values obtained from the calculations are compared with the exterior wall thermal conductivity coefficient for $\left(U_{D}\right)$ Sakarya [2]. Region in TS 825 , all of the values obtained were observed to be higher than the recommended maximum value $\left(U_{D}=0.6\right)$.

Thermal properties of wall elements and

TABLE properties of wall elements.

\begin{tabular}{c|c|c|c|c}
\hline Wall type & $\begin{array}{c}\mathrm{R} \\
{\left[\mathrm{m}^{2} \mathrm{~K} / \mathrm{W}\right]}\end{array}$ & $\begin{array}{c}\mathrm{U}_{D} \\
{\left[\mathrm{~W} / \mathrm{m}^{2} \mathrm{~K}\right]}\end{array}$ & $\begin{array}{c}\mathrm{Q} \\
{\left[\mathrm{W} / \mathrm{m}^{2}\right]}\end{array}$ & $\begin{array}{c}\text { Thermal } \\
\text { conduct. } \\
{[\lambda \mathrm{h}]}\end{array}$ \\
\hline Pumice & 0.81 & 1.02 & 12.19 & 0.19 \\
\hline Gas concrete & 0.82 & 1.01 & 13.07 & 0.24 \\
\hline Cavity wall & 1.29 & 0.68 & 9.30 & 0.15 \\
\hline Block brick & 0.30 & 2.11 & 22.77 & 0.68 \\
\hline $\begin{array}{c}\text { Vertical } \\
\text { coring brick }\end{array}$ & 0.45 & 1.62 & 18.79 & 0.45 \\
\hline $\begin{array}{c}\text { Horizontal } \\
\text { coring brick }\end{array}$ & 0.45 & 1.62 & 18.63 & 0.45
\end{tabular}

\section{Conclusions}

In the studies conducted, when the measured surface temperatures of the materials and different wall materials in terms of heat losses calculated were compared with each other, the below stated results were obtained;

Due to its construction technique and the insulation materials applied, the cavity wall application emerged as the wall type with the highest thermal resistance and lowest amount of heat loss.

For wall surface temperatures, when the pumice block wall's thickness is considered (all the other wall applications were $19 \mathrm{~cm}$ thick, whereas the pumice wall was manufactured with $15 \mathrm{~cm}$ thickness), it was observed that this wall type had the highest conductivity resistance in the heat loss calculations.

The gas concrete wall application was determined to have the highest thermal conductivity resistance after the cavity wall and pumice brick wall applications.

For horizontal and vertical coring bricks, the values of the surface temperatures and heat losses of the two materials were found to be very close.

With its massive structure, the block brick was determined to be the wall material with the lowest thermal 
conductivity resistance and greatest amount of heat loss. The reason for this is that there are no independent air voids in the brick structure.

As a result of the study conducted, the data obtained both by experimental studies and calculation method were determined to be in parallel with the thermal conductivity calculation values $(\lambda \mathrm{h})$.

The $U_{D}$ values obtained by experimental studies and calculations were found to be higher than the recommended maximum value in TS 825. Consequently, when the region in which the structure is built, the wall material type and their thickness values are considered, the necessity of applying thermal insulation in all of the walls is revealed.

\section{References}

[1] A. Bolattürk, Building and Environment 43, 1055 (2008).

[2] M. Tosun, K. Dincer, International Journal of Refrigeration 34, 362 (2011).
[3] G.C. Bakos, Energy and Buildings 31, 251 (2000).

[4] D.T. Chwieduk, Applied Energy 76, 211 (2003).

[5] U.T. Aksoy, Erciyes Univ. Journal of the Institute of Science 24, 277 (2008).

[6] A.K. Dağsöz in: İzocam Tic. San. A.Ş. publications. İstanbul 2002.

[7] C.E. Ekinci in: Ekinci Yapı Tasarımcının İşaat El Kitabı, II Edition., Elazı $\breve{g}$ University publications, Elazı 2003.

[8] G. Bayer, Master Thesis, Sakarya Univ. Journal of the Institute of Science 2006.

[9] L.F. Cabeza, A. Castell, M. Medrano, I. Martorell, G. Perez, I. Fernandez, Energy and Buildings 42, 630 (2010).

[10] N. Daouas, Z. Hassen, H.B. Aissia, Applied Thermal Engineering 30, 319 (2010).

[11] D. A Naouel, Applied Energy 88, 156 (2011).

[12] D.B. Ozkan, C. Onan, Applied Energy 88, 1331 (2011).

[13] A. Ucar, F. Balo, Renewable Energy 35, 88 (2010).

[14] TSE 825. The Turkish Standarts Institute, Ankara 2009.

[15] U.T. Aksoy, Erciyes Univ. Journal of the Institute of Science 24, 277 (2008). 